\title{
ESTIMATIVA DA TEMPERATURA MÉDIA DIÁRIA DO AR EM DISTINTAS REGIÕES BRASILEIRAS EMPREGANDO MÉTODOS ALTERNATIVOS
}

\section{ESTIMATION OF DAILY MEAN AIR TEMPERATURE IN DISTINCT REGIONS OF BRAZIL USING ALTERNATIVE METHODS}

\author{
Daniela JERSZURKI ${ }^{1}$ \\ Jorge Luiz Moretti de SOUZA²
}

\begin{abstract}
RESUMO
O presente trabalho teve por objetivo determinar a confiabilidade de dois métodos alternativos (IAC e Extremos) comumente utilizadas para estimar a temperatura média diária do ar, em relação ao método padrão recomendada pelo Instituto Nacional de Meteorologia (INMET). Os dados de temperatura do ar foram cedidos pelo Instituto Nacional de Pesquisas Espaciais (INPE), compreendendo o período de 2005 e 2008 para doze localidades, situados em dez Estados brasileiro. As análises estatísticas dos dados foram realizadas empregando regressão linear e seus respectivos coeficientes de correlação $(R)$, índice de exatidão (" $d$ ") e índice de desempenho ("c"), tendo o método do INMET como padrão. Os resultados encontrados mostram que o método do IAC estima melhor a temperatura média diária do ar que o método dos Extremos para o período anual e sazonal. $O$ método dos Extremos mostrou sérias restrições para estimar a temperatura média do ar, principalmente nas estações do verão e primavera. Não houve influência da latitude e altitude no desempenho das estimativas da temperatura média diária do ar com os métodos do IAC e Extremos, para as localidades estudas.
\end{abstract}

Palavras-chave: modelos; clima; temperatura do ar.

\begin{abstract}
This study aimed to determine the reliability of two alternative methods (IAC and Max/Min) commonly used to estimate daily mean air temperature in relation to the standard method recommended by the National Institute of Meteorology (INMET). The air temperature data were obtained by the National Institute for Space Research (INPE), between the period 2005 to 2008 for twelve locations, in ten Brazilian States. Statistical analysis of data were made using linear regression and their correlation coefficients $(R)$, precision index ("d") and performance index ("c"), considering INMET method as standard The IAC method showed better results to estimate daily mean air temperature than Max/Min method for annual and seasonal period. The Max/Min method showed serious constraints to estimate the daily mean air temperature, especially in the spring and summer seasons. There was no influence of latitude and altitude on the performance of estimates daily mean air temperature with the IAC and Extremes methods for the localities studied.
\end{abstract}

Key-words: models; climate; air temperature.

\footnotetext{
${ }^{1}$ Engenheira Agrônoma, Universidade Federal do Paraná, Curitiba, PR, Brasil. E-mail: dani_jerszurki@hotmail.com.

${ }^{2}$ Engenheiro Agrícola, Doutor em Irrigação e Drenagem, Professor do Departamento de Solos e Engenharia Agrícola (DSEA), Setor de Ciências Agrárias (SCA), Universidade Federal do Paraná (UFPR). Rua dos Funcionários, 1540. Cep 80035-050, Curitiba, PR, Brasil. E-mail: jmoretti@ufpr.br. Autor para correspondência.
} 
JERSZURKI, D. \& SOUZA, J.L.M. Estimativa da temperatura média diária do...

\section{INTRODUÇÃO}

A temperatura exerce grande influência sobre os processos dinâmicos que ocorrem entre a atmosfera e as plantas, animais, solo, água, entre outros. Reichardt \& Timm (2004) apresentam inúmeros modelos que são utilizados para explicar fenômenos e processos que ocorrem no solo, planta e atmosfera, em que o valor da temperatura está presente.

A temperatura do ar $(t)$ é uma variável contínua em que o valor médio ao longo do dia poderia ser obtido facilmente a partir do "Teorema

do Valor Médio" $f(t)=\frac{\int_{a}^{b} f(t) d t}{b-a} \quad$ (Leithold, 1977), caso a função $f(t)$ fosse sempre a mesma. Contudo, a função $f(t)$ possui alguma tendência ao longo do dia, mas os valores alcançados diferem continuamente ao longo do dia e dos dias do ano, pois a temperatura em um dado instante resulta de uma série de fatores ambientais. Desta forma, a obtenção do valor exato da temperatura média diária do ar necessita da integração de muitas leituras de temperatura do ar ao longo do dia, o que pode tornar a operação difícil e cara. Neste contexto, a estimativa da temperatura média do ar utilizando metodologias padronizadas ou alternativas tornou-se necessária e vem sendo empregada em uma série de atividades envolvendo pesquisas, manejo e planejamento agrícola.

A principal equação utilizada na estimativa da temperatura média do ar é o método elaborado por Serra (1974) e utilizado pelo INMET. Seu desvio médio, em relação à média de 24 observações de temperatura ao longo das horas do dia foi de $-0,8$ ${ }^{\circ} \mathrm{C}$, o que foi considerado satisfatório na época, quando comparada com a fórmula de Kämzt (Nechet \& Preste, 1998).

Andrade et al. (2005) comparando estimativas de temperatura média do ar, verificaram que o método adotado pelo INMET proporcionou melhores estimativas em ambiente protegido do que o método que considera somente temperaturas extremas (máxima e mínima). O resultado obtido neste trabalho é interessante, pois os métodos dos Extremos e IAC são largamente utilizados em inúmeros trabalhos por utilizar apenas temperaturas extremas ou necessitar de menos leituras diárias, respectivamente. Allen et al. (1998), por exemplo, descrevem que a estimativa da evapotranspiração de referência com método de Penman-Monteith (FAO) pode utilizar a temperatura média diária do ar determinada a partir da média das temperaturas máxima e mínima diária (método dos Extremos).

Nesse contexto, a verificação da confiabilidade de métodos utilizados para estimar a temperatura média do ar é importante, visto que valores de temperatura são frequentemente utilizados para avaliar efeitos positivos ou negativos em atividades agrícolas como produção agropecuária, irrigação, zoneamentos agroclimáticos, estudos de mudança climática, entre outras. É interessante observar, inclusive, que inúmeros trabalhos científicos utilizam valores de temperatura média diária, mas não especificam ou dão muita importância ao método utilizado para obter o seu valor, o que pode conduzir a inúmeros erros nos resultados obtidos.

O objetivo do presente trabalho foi determinar a confiabilidade na estimativa diária da temperatura média do ar utilizando dois métodos alternativos, Instituto Agronômico de Campinas (IAC) e Extremos, em relação ao método padrão recomendado pelo Instituto Nacional de Meteorologia (INMET).

\section{MATERIAL E MÉTODOS}

As estimativas da temperatura média do ar foram realizadas empregando três equações. O método recomendado pelo Instituto Nacional de Meteorologia (INMET) foi considerado padrão e, como alternativa, foram testados os métodos do Instituto Agronômico de Campinas (IAC) e Extremos. As Equações 1, 2 e 3 apresentam horário em UTC (Universal Coordinated Time).

Sendo: $t_{\text {med.(INMET) }}$ - temperatura média diária do ar estimada usando o método do Instituto Nacional de Meteorologia $\left({ }^{\circ} \mathrm{C}\right) ; t_{\text {med.(IAC) }}$ - temperatura média diária do ar estimada usando o método do Instituto Agronômico de Campinas $\left({ }^{\circ} \mathrm{C}\right) ; t_{\text {med.(Extremos) }}$ temperatura média diária do ar estimada usando o método dos Extremos $\left({ }^{\circ} \mathrm{C}\right) ; t_{10 n}$ - temperatura do ar medida às dez horas, em UTC $\left({ }^{\circ} \mathrm{C}\right) ; t_{12 h}$ temperatura do ar medida às doze horas, em UTC $\left({ }^{\circ} \mathrm{C}\right) ; t_{17 h}$ - temperatura do ar medida às dezessete horas, em UTC $\left({ }^{\circ} \mathrm{C}\right) ; t_{24 h}$ - temperatura do ar medida às vinte e quatro horas, em UTC $\left({ }^{\circ} \mathrm{C}\right) ; t_{M A X}-$ temperatura diária máxima do ar $\left({ }^{\circ} \mathrm{C}\right) ; t_{M I N}$ temperatura diária mínima do ar $\left({ }^{\circ} \mathrm{C}\right) .{ }^{*} t_{10 h} \mathrm{e}{ }^{*} t_{17 h}-\dot{E}$ importante considerar, para o método do IAC (Equação 2), que foram utilizadas temperatura do ar as 9:00 h (UTC) e 18:00 h (UTC), ao invés da temperatura do ar às 10:00 h $\left(T_{10 \mathrm{~h}}\right)$ e 17:00 h $\left(T_{17 \mathrm{~h}}\right)$, respectivamente, conforme método original, por não haver leituras neste horário na série de dados do Centro de Previsão de Tempo e Estudos Climáticos (CPTEC) / Instituto Nacional de Pesquisas Espaciais (INPE).

Doze localidades de dez Estados brasileiro foram escolhidas para serem analisadas por situarem-se em diferentes latitudes, altitudes e longitudes, conforme pode ser verificado na Tabela 1.Os dados diários de temperatura do ar ( $T_{\text {MAX }}, T_{\text {MIN }}$, $T_{9 h}, T_{12 h}, T_{18 h}, T_{24 h}$, em UTC), para as localidades analisadas, foram obtidos e tabulados a partir da série histórica da rede de estações PCD's (Plataformas de Coleta de Dados) do Instituto Nacional de Pesquisas Espaciais (INPE). Foram utilizados dados dos anos de 2005 a 2008, conforme arquivos do Centro de Previsão de Tempo e Estudos Climáticos (CPTEC) (Brasil, 2009), que disponibiliza dados diários com leituras de temperatura a cada $3 \mathrm{~h}$, realizadas (horário em UTC) as zero hora $(0: 0 \mathrm{~h})$, três horas $(3: 00 \mathrm{~h})$, seis horas $(6: 00 \mathrm{~h})$, nove horas $(9: 00 \mathrm{~h})$, doze horas $(12: 00 \mathrm{~h})$, quinze horas $(15: 00 \mathrm{~h})$, dezoito horas $(18: 00 \mathrm{~h})$ e vinte e uma horas $(21: 00 \mathrm{~h})$. 


$$
\begin{aligned}
& t_{\text {med(INMET) }}=\frac{t_{12 h}+2 \cdot t_{24 h}+t_{M a x}+t_{M i n}}{5} \\
& t_{\text {med(IAC) }}=\frac{* t_{10 h}+* t_{17 h}+2 \cdot t_{24 h}}{4} \\
& t_{\text {med(Extremos) }}=\frac{t_{\text {Max }}+t_{\text {Min }}}{2}
\end{aligned}
$$

TABELA 1 - Latitude, longitude, altitude e classificação climática segundo Köppen, das localidades utilizadas nas análises de estimativa da temperatura média.

\begin{tabular}{lccccc}
\hline \multicolumn{1}{c}{ Cidade } & Estado & $\begin{array}{c}\text { Latitude } \\
\text { (graus) }\end{array}$ & $\begin{array}{c}\text { Longitude } \\
\text { (graus) }\end{array}$ & $\begin{array}{c}\text { Altitude } \\
(\mathrm{m})\end{array}$ & Clima \\
\hline Belém de São Francisco & $\mathrm{PE}$ & $-8,76^{\circ}$ & $-38,98^{\circ}$ & 318 & BShW \\
Campo Grande & $\mathrm{MS}$ & $-20,50^{\circ}$ & $-54,62^{\circ}$ & 530 & $\mathrm{Cfa} / \mathrm{Aw}$ \\
Caxias do Sul & $\mathrm{RS}$ & $-29,14^{\circ}$ & $-50,98^{\circ}$ & 740 & $\mathrm{Cfb}$ \\
Itaporanga & $\mathrm{PB}$ & $-7,36^{\circ}$ & $-38,20^{\circ}$ & 323 & $\mathrm{Aw}$ \\
Jaboticabal & $\mathrm{SP}$ & $-21,24^{\circ}$ & $-48,30^{\circ}$ & 600 & Cwa \\
Jandaia & $\mathrm{GO}$ & $-17,24^{\circ}$ & $-50,12^{\circ}$ & 550 & $\mathrm{Aw}$ \\
Lavras & $\mathrm{MG}$ & $-21,22^{\circ}$ & $-44,97^{\circ}$ & 960 & $\mathrm{Cwa}$ \\
Nova Cantu & $\mathrm{PR}$ & $-24,68^{\circ}$ & $-52,58^{\circ}$ & 545 & $\mathrm{Cfb}$ \\
Rio Preto da Eva & $\mathrm{AM}$ & $-2,42^{\circ}$ & $-59,87^{\circ}$ & 50 & $\mathrm{Amw}$ \\
Santa Vitória & $\mathrm{MG}$ & $-19,50^{\circ}$ & $-50,00^{\circ}$ & 492 & $\mathrm{Aw}$ \\
São Borja & $\mathrm{RS}$ & $-28,69^{\circ}$ & $-55,96^{\circ}$ & 96 & $\mathrm{Cfa}$ \\
Venda Nova do Imigrante & $\mathrm{ES}$ & $-20,38^{\circ}$ & $-41,19^{\circ}$ & 727 & $\mathrm{Cwa}$ \\
\hline
\end{tabular}

Conforme descrito em Brasil (2009), o sensor de temperatura das PCD's está localizado dentro de um invólucro protegido por um filtro poroso (goretex), protegido contra poeira e água. Para evitar exposição direta do elemento sensor à chuva e aos raios solares e também garantir que os mesmos recebam adequada ventilação para permitir o equilíbrio com a atmosfera a sua volta, o conjunto é protegido por uma espécie de chapéu que pode ser de plástico ou alumínio. O elemento sensor de temperatura do ar é um resistor de platina que possui uma estável e calibrada relação entre resistência elétrica e temperatura. As variações de resistência são medidas por um circuito eletrônico que apresenta em sua saída uma tensão contínua com $1,0 \mathrm{~V}$, representando $+70{ }^{\circ} \mathrm{C}$ e, $0,0 \mathrm{~V}$, representando $-30^{\circ} \mathrm{C}$.

As análises estatísticas para verificar as estimativas da temperatura média diária do ar com os métodos do IAC e Extremos (alternativas), em relação à temperatura média diária do ar estimada com o método recomendado pelo INMET (padrão), foram realizadas empregando análises de regressão linear e seu respectivo coeficiente de correlação $(R)$. Foram realizadas análises para cada localidade considerando:

Procedimento 1: análises de regressão linear contrastando as estimativas diárias de temperatura média do ar $\left({ }^{\circ} \mathrm{C}\right), T_{\text {med.(INMET) }} v s T_{\text {med.(IAC) }}$ e $T_{\text {med.(INMET) }}$ vs $T_{\text {med.(Extremos), considerando todos os dias dos }}$ anos e estações dos anos (verão, outono, inverno e primavera) entre 2005 e 2008, para doze localidades brasileiras (12 valores de $R$ para cada ano e estações);

Procedimento 2: análises de regressão linear contrastando as estimativas diárias de temperatura média do ar $\left({ }^{\circ} \mathrm{C}\right), T_{\text {med.(INMET }}$ vs $T_{\text {med.(IAC) }}$ e $T_{\text {med.(INMET) }}$ vs $T_{\text {med.(Extremos), considerando separadamente os }}$ dias de cada ano e estações de cada ano (verão, outono, inverno e primavera) entre 2005 e 2008, para doze localidades brasileiras (4 anos . 12 localidades $=48$ valores de $R$ para cada ano $\mathrm{e}$ estações).

Na organização dos dados por estações do ano, considerou-se: o verão ocorrendo entre 21 de dezembro e 20 de março; o outono ocorrendo entre 
21 de março e 20 de junho; o inverno entre 21 de junho e 22 de setembro; e, a primavera entre 23 de setembro e 20 de dezembro.

Para avaliar o grau de exatidão entre valores de temperatura média diária do ar, estimada com o método do INMET (padrão) e métodos do IAC e Extremos (alternativas), conforme Procedimentos 1 e 2, utilizou-se o índice " $d$ " de concordância ou exatidão de Willmott et al. (1985).

$$
d=1-\left[\frac{\sum_{i=1}^{n}\left(T_{\text {med Alternativo } i}-T_{\text {med }(\text { INMET })_{i}}\right)^{2}}{\sum_{i=1}^{n}\left(\left|T_{\text {med Alternativo } i}-\bar{T}_{\text {med }(\text { INMET })}\right|+\left|T_{\text {med }(\text { INMET })_{i}}-\bar{T}_{\text {med }(\text { INMET })}\right|\right)^{2}}\right]
$$

Sendo: $d$ - índice de concordância ou exatidão de Willmott et al. (1985);

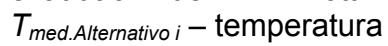

média do ar estimada no $i$-ésimo dia com o método do IAC ou Extremos $\left({ }^{\circ} \mathrm{C}\right) ; T_{\text {med.(INMET) } i}$ - temperatura média do ar estimada com o método do INMET no $i$ -

$$
\begin{gathered}
\text { ésimo dia }\left(\mathrm{C}^{\circ}\right) ; \bar{T}_{\text {med.(INMET) }} \text { - média das } \\
c=|R \cdot d|
\end{gathered}
$$

Sendo: $c$ - índice "c" de desempenho proposto por Camargo \& Sentelhas (1997) (adimensional); $R$ coeficiente de correlação (adimensional) calculado para a regressão linear (adimensional); $d$ - índice " $d$ " de concordância proposto por Willmott et al. (1985) (adimensional). O critério de interpretação do índice " $c$ " tem os seguintes desempenhos: ótimo (" $c$ " > 0,85); muito bom $(0,75<$ " $c$ " $\leq 0,85)$; bom $(0,65<$ <" $c$ " 0,75); mediano $(0,60<" c$ " $\leq 0,65)$; sofrível $(0,50<$ " $c$ " $\leq 0,60)$; mau $(0,40<$ " $c$ " $\leq 0,50)$; e, péssimo ("c" $\leq 0,40)$.

Foram realizadas, também, análises de regressão linear entre os valores de latitude e altitude das localidades em estudo verso os coeficientes $(R)$ e índices (" $d$ " e " $c$ ") obtidos com os Procedimentos 1 e 2 para os períodos anual e sazonal (verão, outono, inverno e primavera), com os contrastes: $T_{\text {med.(INMET) }} v s T_{\text {med.(IAC) }}$ e $T_{\text {med.(INMET) }} v s$ $T_{\text {med.(Extremos). }}$.

\section{RESULTADOS E DISCUSSÃO}

A série de dados diários disponibilizada pelo Instituto Nacional de Pesquisas Espaciais (INPE) / Centro de Previsão de Tempo e Estudos Climáticos (CPTEC) (Brasil, 2009), para as localidades estudadas, não foi muito grande (entre 2005 e 2008). No entanto, é importante enfatizar que as análises de regressão linear ( $T_{\text {med.(INMET) }} v s$ $T_{\text {med.(IAC) }}$ e $T_{\text {med.(INMET) }}$ vs $T_{\text {med.(Extremos) }}$ ) realizadas para períodos anuais e estações no ano de cada uma das dose localidades, conforme Procedimento 1 , tiveram em média 1268 dias para o período anual e $322,335,333$ e 278 dias para as estações do verão, outono, inverno e primavera, temperaturas médias diárias do ar, estimada com o método do INMET no período considerado $\left({ }^{\circ} \mathrm{C}\right) ; n-$ número de dias.

Para comparação, utilizou-se uma adaptação do índice de desempenho "c" adotado por Camargo \& Sentelhas (1997), que serve como indicador de desempenho dos métodos alternativos

respectivamente (Tabela 2 ). As análises realizadas considerando o Procedimento 2 tiveram em média 317 dias para o períodos anuais e $84,87,84$ e 78 dias para as estações do verão, outono, inverno e primavera, respectivamente. Desta forma as amostras de coeficiente $(R)$ e índices (" $d$ " e "c") foram de 12 pontos para as análises considerando o Procedimento 1 e variaram entre 44 e 48 pontos para cada ano ou estação analisada seguindo o Procedimento 2. Conforme recomendações de Naghettini \& Pinto (2007) e observando inúmeros exemplos verificados na literatura (Lima \& Ribeiro, 1998; Nechet \& Preste, 1998; Pezzopane et al., 2004; Andrade et al., 2005; Cargnelutti Filho et al., 2006), considerou-se que a série de dados utilizada foi representativa e suficiente para alcançar os objetivos do trabalho.

Os piores resultados obtidos na estimativa da temperatura média do ar, conforme Procedimento 1, considerando análises " $T_{\text {med.(INMET) }}$ vs $T_{\text {med.(IAC)" e " }} T_{\text {med.(INMET) }} v s T_{\text {med.(Extremos)" para as }}$ doze localidades (Tabela 2), ocorreram na estação da primavera, tanto para a localidade de Itaporanga -PB (184 dias, $R=0,65$, " $d "=0,66$ e " $c$ " $=0,42$ ) como Rio Preto da Eva-AM (105 dias, $R=0,49$, " $d$ " $=0,69$ e "c" $=0,33$ ). Os piores resultados ocorreram nas duas localidades possuindo menor número de dias de temperaturas média do ar, o que pode indicar maiores dificuldades de operação destas duas PCD's. Itaporanga-PR também apresentou o segundo pior resultado nas análises com o método do IAC, que ocorreu para a estação do inverno (262 dias; $R=0,79$; " $d "=0,79$ e " $c$ " = 0,62). 
JERSZURKI, D. \& SOUZA, J.L.M. Estimativa da temperatura média diária do...

TABELA 2 - Coeficiente de correlação $(R)$, índice "d" de Willmott et al. (1985) e índice "c" de Camargo \& Sentelhas (1997), obtidos nas análises contrastando a temperatura média diária do ar determinada com os métodos do INMET $\left(T_{\text {med } \tau \text { (INMET })}\right)$, IAC $\left(T_{\text {med }(I A C)}\right)$ e Extremos $\left(T_{\text {med }(E x t r e m o s)}\right)$, considerando todos os dias dos anos e estações dos anos entre 2005 e 2008, para doze localidades brasileiras (Procedimento 1).

\begin{tabular}{|c|c|c|c|c|c|c|c|c|}
\hline \multirow{2}{*}{ Cidade } & \multirow[b]{2}{*}{ Ano } & \multirow{2}{*}{ Dias } & \multicolumn{3}{|c|}{ 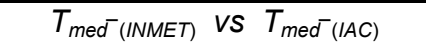 } & \multicolumn{3}{|c|}{$\begin{array}{lll}T_{\text {med }(I N M E T)} & \text { VS } & T_{\text {med }} \text { (Extremos) }\end{array}$} \\
\hline & & & $R$ & "d" & "c" & $R$ & "d" & "c" \\
\hline \multirow{5}{*}{$\begin{array}{l}\text { Belém do São } \\
\text { Francisco-PE }\end{array}$} & Anos & 1069 & 0,94 & 0,95 & 0,89 & 0,95 & 0,96 & 0,92 \\
\hline & Verão & 249 & 0,86 & 0,87 & 0,75 & 0,83 & 0,89 & 0,74 \\
\hline & Outono & 260 & 0,94 & 0,92 & 0,87 & 0,90 & 0,88 & 0,79 \\
\hline & Inverno & 292 & 0,91 & 0,88 & 0,80 & 0,91 & 0,93 & 0,84 \\
\hline & Primavera & 268 & 0,83 & 0,84 & 0,69 & 0,92 & 0,95 & 0,87 \\
\hline \multirow{5}{*}{$\begin{array}{c}\text { Campo Grande- } \\
\text { MS }\end{array}$} & Anos & 1403 & 0,94 & 0,95 & 0,90 & 0,88 & 0,94 & 0,83 \\
\hline & Verão & 349 & 0,84 & 0,89 & 0,75 & 0,69 & 0,81 & 0,56 \\
\hline & Outono & 358 & 0,96 & 0,96 & 0,92 & 0,92 & 0,96 & 0,88 \\
\hline & Inverno & 362 & 0,97 & 0,96 & 0,93 & 0,91 & 0,95 & 0,87 \\
\hline & Primavera & 334 & 0,89 & 0,91 & 0,81 & 0,73 & 0,85 & 0,62 \\
\hline \multirow{5}{*}{$\begin{array}{c}\text { Caxias do Sul- } \\
\text { RS }\end{array}$} & Anos & 1338 & 0,96 & 0,97 & 0,93 & 0,93 & 0,95 & 0,89 \\
\hline & Verão & 326 & 0,89 & 0,92 & 0,81 & 0,79 & 0,84 & 0,67 \\
\hline & Outono & 365 & 0,96 & 0,97 & 0,93 & 0,92 & 0,94 & 0,87 \\
\hline & Inverno & 375 & 0,95 & 0,97 & 0,93 & 0,93 & 0,95 & 0,89 \\
\hline & Primavera & 272 & 0,89 & 0,93 & 0,82 & 0,82 & 0,89 & 0,73 \\
\hline \multirow{5}{*}{ Itaporanga-PB } & Anos & 1109 & 0,89 & 0,91 & 0,81 & 0,89 & 0,91 & 0,81 \\
\hline & Verão & 328 & 0,90 & 0,91 & 0,81 & 0,86 & 0,90 & 0,77 \\
\hline & Outono & 335 & 0,87 & 0,92 & 0,80 & 0,89 & 0,84 & 0,75 \\
\hline & Inverno & 262 & 0,79 & 0,79 & 0,62 & 0,82 & 0,86 & 0,71 \\
\hline & Primavera & 184 & 0,65 & 0,66 & 0,42 & 0,75 & 0,86 & 0,65 \\
\hline \multirow{5}{*}{ Jaboticabal-SP } & Anos & 1393 & 0,94 & 0,94 & 0,89 & 0,91 & 0,95 & 0,86 \\
\hline & Verão & 343 & 0,89 & 0,89 & 0,80 & 0,63 & 0,78 & 0,50 \\
\hline & Outono & 357 & 0,94 & 0,94 & 0,89 & 0,94 & 0,95 & 0,89 \\
\hline & Inverno & 358 & 0,95 & 0,92 & 0,87 & 0,92 & 0,95 & 0,88 \\
\hline & Primavera & 335 & 0,91 & 0,90 & 0,82 & 0,79 & 0,88 & 0,70 \\
\hline \multirow{5}{*}{ Jandaia-GO } & Anos & 1390 & 0,90 & 0,90 & 0,81 & 0,86 & 0,92 & 0,80 \\
\hline & Verão & 343 & 0,92 & 0,92 & 0,85 & 0,57 & 0,72 & 0,41 \\
\hline & Outono & 358 & 0,92 & 0,90 & 0,83 & 0,91 & 0,93 & 0,85 \\
\hline & Inverno & 360 & 0,93 & 0,86 & 0,80 & 0,92 & 0,95 & 0,87 \\
\hline & Primavera & 329 & 0,92 & 0,91 & 0,83 & 0,75 & 0,83 & 0,62 \\
\hline \multirow{5}{*}{ Lavras-MG } & Anos & 1311 & 0,93 & 0,95 & 0,88 & 0,92 & 0,93 & 0,85 \\
\hline & Verão & 317 & 0,91 & 0,92 & 0,83 & 0,71 & 0,79 & 0,56 \\
\hline & Outono & 357 & 0,93 & 0,94 & 0,88 & 0,95 & 0,93 & 0,88 \\
\hline & Inverno & 367 & 0,91 & 0,90 & 0,82 & 0,92 & 0,93 & 0,86 \\
\hline & Primavera & 270 & 0,90 & 0,93 & 0,84 & 0,79 & 0,84 & 0,66 \\
\hline \multirow{5}{*}{ Nova Cantu-PR } & Anos & 1108 & 0,95 & 0,96 & 0,92 & 0,93 & 0,96 & 0,90 \\
\hline & Verão & 271 & 0,89 & 0,89 & 0,80 & 0,72 & 0,83 & 0,60 \\
\hline & Outono & 272 & 0,96 & 0,96 & 0,92 & 0,94 & 0,97 & 0,91 \\
\hline & Inverno & 275 & 0,95 & 0,96 & 0,92 & 0,94 & 0,97 & 0,90 \\
\hline & Primavera & 290 & 0,89 & 0,91 & 0,81 & 0,81 & 0,89 & 0,72 \\
\hline
\end{tabular}


JERSZURKI, D. \& SOUZA, J.L.M. Estimativa da temperatura média diária do...

\begin{tabular}{|c|c|c|c|c|c|c|c|c|}
\hline \multirow{5}{*}{$\begin{array}{c}\text { Rio Preto da } \\
\text { Eva - AM }\end{array}$} & \multirow{2}{*}{$\begin{array}{l}\text { Anos } \\
\text { Verão }\end{array}$} & 1004 & 0,92 & 0,95 & 0,87 & 0,85 & 0,93 & 0,80 \\
\hline & & 315 & 0,85 & 0,89 & 0,75 & 0,62 & 0,75 & 0,47 \\
\hline & \multirow{2}{*}{$\begin{array}{l}\text { Outono } \\
\text { Inverno }\end{array}$} & 313 & 0,94 & 0,96 & 0,90 & 0,88 & 0,92 & 0,81 \\
\hline & & 271 & 0,92 & 0,95 & 0,87 & 0,90 & 0,94 & 0,84 \\
\hline & Primavera & 105 & 0,88 & 0,91 & 0,80 & 0,49 & 0,69 & 0,33 \\
\hline \multirow{5}{*}{$\begin{array}{c}\text { Santa Vitória- } \\
\text { MG }\end{array}$} & \multirow{2}{*}{$\begin{array}{l}\text { Anos } \\
\text { Verão }\end{array}$} & 1340 & 0,92 & 0,93 & 0,86 & 0,89 & 0,94 & 0,84 \\
\hline & & 337 & 0,86 & 0,89 & 0,77 & 0,69 & 0,79 & 0,54 \\
\hline & \multirow{2}{*}{$\begin{array}{l}\text { Outono } \\
\text { Inverno }\end{array}$} & 360 & 0,95 & 0,93 & 0,89 & 0,94 & 0,96 & 0,90 \\
\hline & & 355 & 0,95 & 0,93 & 0,89 & 0,93 & 0,96 & 0,89 \\
\hline & Primavera & 288 & 0,90 & 0,91 & 0,82 & 0,76 & 0,86 & 0,65 \\
\hline \multirow{5}{*}{ São Borja - RS } & \multirow{5}{*}{$\begin{array}{l}\text { Anos } \\
\text { Verão } \\
\text { Outono } \\
\text { Inverno } \\
\text { Primavera }\end{array}$} & 1393 & 0,97 & 0,98 & 0,95 & 0,96 & 0,98 & 0,93 \\
\hline & & 343 & 0,86 & 0,90 & 0,77 & 0,74 & 0,82 & 0,61 \\
\hline & & 356 & 0,98 & 0,99 & 0,97 & 0,97 & 0,98 & 0,96 \\
\hline & & 360 & 0,97 & 0,98 & 0,95 & 0,95 & 0,97 & 0,92 \\
\hline & & 334 & 0,96 & 0,96 & 0,92 & 0,91 & 0,95 & 0,86 \\
\hline \multirow{5}{*}{$\begin{array}{l}\text { Venda Nova } \\
\text { Imigrante-ES }\end{array}$} & \multirow{2}{*}{$\begin{array}{l}\text { Anos } \\
\text { Verão }\end{array}$} & 1356 & 0,97 & 0,98 & 0,94 & 0,95 & 0,94 & 0,90 \\
\hline & & 345 & 0,94 & 0,95 & 0,89 & 0,88 & 0,87 & 0,77 \\
\hline & \multirow{2}{*}{$\begin{array}{l}\text { Outono } \\
\text { Inverno }\end{array}$} & 329 & 0,98 & 0,98 & 0,96 & 0,98 & 0,96 & 0,93 \\
\hline & & 355 & 0,90 & 0,91 & 0,81 & 0,84 & 0,80 & 0,68 \\
\hline & Primavera & 327 & 0,93 & 0,96 & 0,89 & 0,91 & 0,89 & 0,81 \\
\hline
\end{tabular}

Em média, considerando as doze localidades, os valores de $R$ (Tabela 2 ) nas análises foram: " $T_{\text {med.(INMET) }} v S T_{\text {med.(IAC)" }}$ - iguais a 0,94, 0,88, $0,94,0,93$ e 0,88 , respectivamente, para os períodos anual, verão, outono, inverno e primavera;

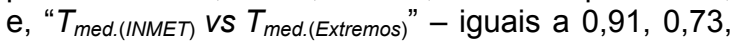
$0,93,0,91$ e 0,79 , respectivamente, para os períodos anual, verão, outono, inverno e primavera.

De maneira geral, o método do IAC demonstrou melhores resultados na estimativa da temperatura média do ar ( $T_{\text {med.(INMET) }} v s T_{\text {med.(IAC) }) \text {, }}$ quando comparada ao método dos Extremos ( $T_{\text {med. }}$. (INMET) VS $T_{\text {med.(Extremos) }}$ ), conforme pode ser verificado na Tabela 3 e Figura 1, que apresentam a frequência dos índices de desempenho " $c$ " a partir dos resultados apresentados na Tabela 2.

Considerando apenas o período anual (Tabela 3 e Figura 1), verificou-se que $100 \%$ das análises obtiveram índice " $c$ " de desempenho entre "ótimo" ("c" > 0,85) e "muito bom" $(0,75<$ "c" $\leq 0,85)$ para os métodos do IAC $\left(T_{\text {med.(IAC) }}\right)$ e Extremos

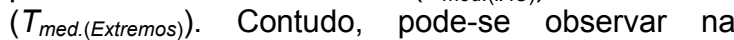
mesma tabela e figura, dentre as estações do ano, que os melhores resultados de desempenho ocorreram para o outono e inverno, em que o índice " $c$ " de desempenho das análises prevaleceu entre "ótimo" e "muito bom", demonstrando que o período do ano interferiu nos resultados dos métodos alternativos de estimativa da temperatura média do ar.
As análises $T_{\text {med.(INMET) }}$ vs $T_{\text {med.(IAC) }}$ indicaram índices de desempenho " $C$ " para o método do IAC (Tabela 3 e Figura 1a) entre "bom" $(0,65<$ "c" $\leq 0,75)$ e "ótimo" ("c" > 0,85) em mais de $90 \%$ dos resultados, prevalecendo "ótimo" para o período anual $(83,3 \%)$, estações do outono $(83,3 \%)$ e inverno $(58,3 \%)$ e, "muito bom" $(0,75<$ "c" $\leq 0,85)$, para as estações do verão $(66,7 \%)$ e primavera $(66,7 \%)$. As estações do inverno e primavera chegaram a registrar índice de desempenho " $c$ " "mediano" $(8,3 \%)$ e "mau" $(8,3 \%)$.

Com exceção da estação do verão, as análises $T_{\text {med.(INMET) }}$ vs $T_{\text {med.(Extremos) }}$ indicaram índices de desempenho " $c$ " para o método dos Extremos (Tabela 3 e Figura 1b) entre "mediano" $(0,60<$ "c" $\leq 0,65)$ e "ótimo" ("c" > 0,85) em mais de $90 \%$ dos resultados. A estação do verão mostrou maior dispersão dos resultados, sendo interessante observar que $58,3 \%$ dos índices de desempenho " $c$ " ficaram classificados como "sofrível" $(0,50<$ " $c$ " $\leq 0,60)$ e "mau" $(0,40<$ " $c$ " $\leq$ $0,50)$. Apenas $16,7 \%$ dos resultados para as estações do verão obtiveram desempenho "muito bom" e nenhum índice "ótimo" foi registrado. Desta forma, o método dos Extremos apresentou maiores restrições para estimar a temperatura média do ar nas localidades analisadas e os resultados obtidos para a estação do verão indicam que o método tem de ser utilizado com muita cautela. 
JERSZURKI, D. \& SOUZA, J.L.M. Estimativa da temperatura média diária do...

TABELA 3 - Frequência do índice de desempenho "c" de Camargo \& Sentelhas (1997) obtidos a partir da Tabela 2, nas análises contrastando a temperatura média diária do ar estimada com os métodos do INMET $\left(T_{\text {med }(\text { INMET })}\right)$, IAC $\left(T_{\text {med }(I A C)}\right)$ e Extremos $\left(T_{\text {med }}(\right.$ Extremos $)$, conforme procedimento $1^{* *}$

\begin{tabular}{|c|c|c|c|c|c|c|c|}
\hline \multirow{3}{*}{$\begin{array}{l}\text { Análise / } \\
\text { Período }\end{array}$} & \multicolumn{7}{|c|}{ 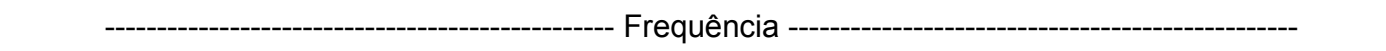 } \\
\hline & Ótimo & Muito Bom & Bom & Mediano & Sofrível & Mau & Péssimo \\
\hline & (unid.) (\%) & (unid.) (\%) & (unid.) (\%) & (unid.) (\%) & (unid.) (\%) & (unid.) (\%) & (unid.) (\%) \\
\hline
\end{tabular}

\begin{tabular}{ccccccccccccccc}
\multicolumn{1}{l}{$\begin{array}{l}\text { Análises entre a temperatura média diária do ar: } \\
\text { Anual }\end{array}$} & 10 & 83,3 & 2 & 16,7 & 0 & 0,0 & 0 & 0,0 & 0 & 0,0 & 0 & 0,0 & 0 & 0,0 \\
Verão & 1 & 8,3 & 8 & 66,7 & 3 & 25,0 & 0 & 0,0 & 0 & 0,0 & 0 & 0,0 & 0 & 0,0 \\
Outono & 10 & 83,3 & 2 & 16,7 & 0 & 0,0 & 0 & 0,0 & 0 & 0,0 & 0 & 0,0 & 0 & 0,0 \\
Inverno & 7 & 58,3 & 4 & 33,3 & 0 & 0,0 & 1 & 8,3 & 0 & 0,0 & 0 & 0,0 & 0 & 0,0 \\
Primavera & 2 & 16,7 & 8 & 66,7 & 1 & 8,3 & 0 & 0,0 & 0 & 0,0 & 1 & 8,3 & 0 & 0,0 \\
\hline
\end{tabular}

Análises entre a temperatura média diária do ar: $T_{\text {med_lINMET) }}$ vs $T_{\text {med_(Extremos) }}$

\begin{tabular}{ccccccccccccccc} 
Anual & 6 & 50,0 & 6 & 50,0 & 0 & 0,0 & 0 & 0,0 & 0 & 0,0 & 0 & 0,0 & 0 & 0,0 \\
Verão & 0 & 0,0 & 2 & 16,7 & 2 & 16,7 & 1 & 8,3 & 4 & 33,3 & 3 & 25,0 & 0 & 0,0 \\
Outono & 8 & 66,7 & 3 & 25,0 & 1 & 8,3 & 0 & 0,0 & 0 & 0,0 & 0 & 0,0 & 0 & 0,0 \\
Inverno & 8 & 66,7 & 2 & 16,7 & 2 & 16,7 & 0 & 0,0 & 0 & 0,0 & 0 & 0,0 & 0 & 0,0 \\
Primavera & 2 & 16,7 & 1 & 8,3 & 4 & 33,3 & 4 & 33,3 & 0 & 0,0 & 0 & 0,0 & 1 & 8,3 \\
\hline ** Procedimento 1: Análise considerando todos os dias dos anos e estações dos anos entre 2005 e 2008 para doze
\end{tabular}
localidades brasileiras (12 pontos para cada ano e estação)

(a)

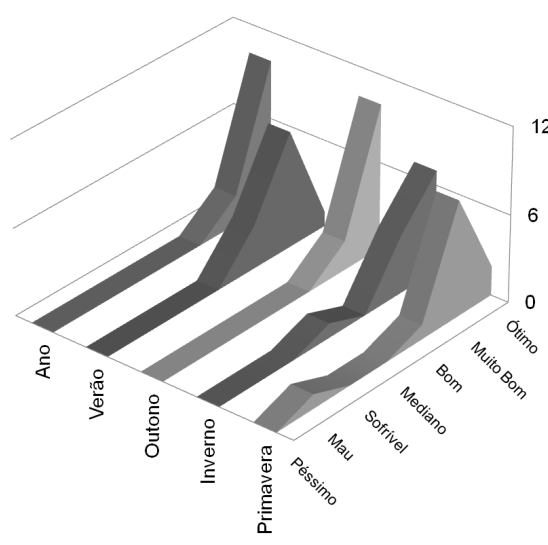

Indice de desempenho " $c$ "

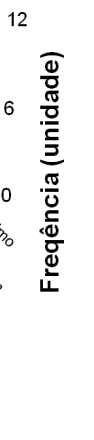

(b)

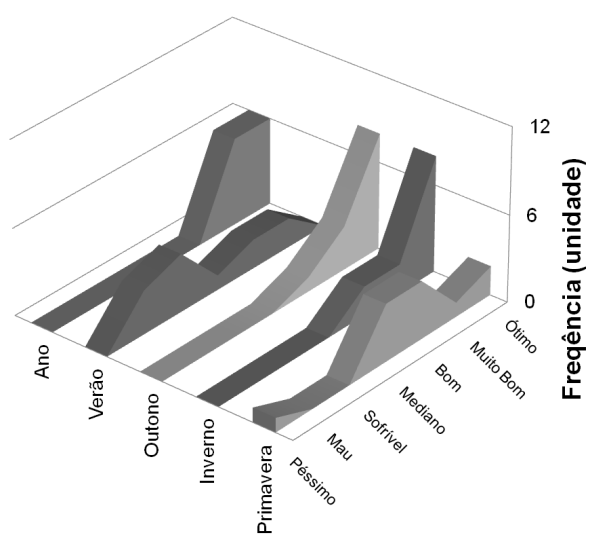

Indice de desempenho " $c$ "

FIGURA 1 - Frequência dos índices de desempenho "c" de Camargo \& Sentelhas (1997) obtidos nas análises realizadas conforme Procedimento 1, para os anos e estações do ano, contrastando: (a) $T_{\text {med_ }}$

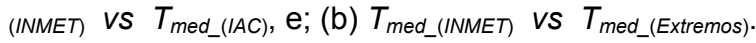

A restrição verificada para o método dos Extremos no presente trabalho também foi indiretamente evidenciada por outros autores. Andrade et al. (2005) estudaram as estimativas de temperatura média do ar em ambiente protegido do período entre o final da primavera ao início de verão (24 de novembro a 31 de janeiro) e verificaram, em comparação à média de 96 leituras diárias de temperatura do ar (denominada pelos autores como "real"), que o coeficiente de determinação $\left(R^{2}\right)$ ficaram em: 0,9085 para a relação temperatura "real" versus INMET; e, 0,8390 para a relação temperatura "real" versus método dos Extremos. Desta forma, o método dos Extremos explicou menos $6,95 \%$ das temperaturas médias "reais" que o método do INMET. Da mesma forma, Nechet \& Preste (1998) compararam a temperatura média do ar obtida de 24 leituras diárias (denominada pelos autores como "padrão") com a temperatura média diária do ar estimada com os métodos do INMET (compensada) e Extremos ("máxima e mínima"). As análises foram realizadas para os anos de 1996 e 1997, considerando três meses mais representativos da época chuvosa e menos 
chuvosa. Os autores verificaram que a utilização das temperaturas médias do ar obtidas com o método do INMET (temperaturas compensadas) tiveram seus valores muito próximos aos encontrados pelo método "padrão", apresentando menores desvios que o método dos Extremos, que considera apenas as temperaturas diárias extremas do ar (máxima e mínima). Tanto Andrade et al. (2005) como Nechet \& Preste (1998) não analisaram estatisticamente o ajustamento entre as temperaturas médias diárias obtidas com os métodos do INMET e Extremos, no entanto, indiretamente, é possível afirmar (inferir) para os dois trabalhos que o método do INMET não se mostrou bem ajustada com a temperatura média diária do ar obtida com o método dos Extremos nas duas localidades e períodos analisados.

Os resultados obtidos até o momento sugerem que as estimativas de temperatura média diária do ar prevaleceram, em mais de $90 \%$ dos resultados, com índices de desempenho entre "bom" e "ótimo" para o método do IAC e entre "mediano" e "ótimo" para o método dos Extremos. No entanto, não se deve esquecer que a temperatura média diária do ar frequentemente é utilizada em modelos que multiplicam ou elevam o seu valor a potência, conforme pode ser visto em Reichardt \& Timm (2004). Desta forma, considerando as saídas obtidas em determinados modelos, como cálculo da evapotranspiração de referência, soma térmica, balanço de energia, fluxo de calor, entre outros, pode-se encontrar maiores ou menores variações dos valores do coeficiente $R$ e índices " $d$ " e " $c$ ", nas análises envolvendo o resultado obtido com as duas equações testadas.
A Tabela 4 e Figura 2 apresentam a frequência dos índices de desempenho " $c$ " de Camargo \& Sentelhas (1997) obtidos nas análises contrastando a temperatura média diária do ar, $T_{\text {med }}$ (INMET) VS $T_{\text {med.(IAC) }}$ e $T_{\text {med.(INMET) }}$ vs $T_{\text {med.(Extremos), }}$ considerando separadamente os dias de cada ano e estações de cada ano (verão, outono, inverno e primavera) entre 2005 e 2008, para doze localidades brasileiras (Procedimento 2). Não se pode descartar a possibilidade da interferência de falhas de leituras de temperatura diária nas séries de dados, no entanto, a frequência dos desempenhos disposta na Tabela 4 e Figura 3 originou-se quase sempre de dados de temperatura média do ar de doze cidades e quatro anos ou estações, perfazendo amostras que variaram entre 44 e 48 desempenhos (pontos) para cada ano ou estação analisada. É importante observar que amostras possuindo tamanho $N \geq 30$ são consideradas estatisticamente de tamanho grande (Naghettini \& Pinto, 2007). Com maior número de valores de índice de desempenho " $c$ " (entre 44 e 48), analisados conforme Procedimento 2, houve naturalmente maior dispersão dos resultados entre as classes, indo de "péssimo" a "ótimo" (Tabela 4 e Figura 2). Contudo, desconsiderando a grandeza dos valores, verificou-se que a tendência (Figura 1 e 2) dos resultados obtidos nas análises com os Procedimento 1 e 2 são muito parecidas e as discussões e observações feitas anteriormente para os resultados apresentados nas Tabelas 2 e 3 e Figura 1 (Procedimento 1) permanecem válidas para as análises realizadas conforme 0 Procedimento 2.

TABELA 4 - Frequência do índice de desempenho "c" de Camargo \& Sentelhas (1997), obtidos nas análises contrastando a temperatura média diária do ar estimada com os métodos do INMET $\left(T_{\text {med }}\right.$ (INMET) $)$, IAC $\left(T_{\text {med }{ }^{\top}(I A C)}\right)$ e método dos Extremos $\left(T_{\text {med }}(\right.$ Extremos $)$, conforme procedimento $2^{* *}$

\begin{tabular}{|c|c|c|c|c|c|c|c|c|c|c|c|c|c|c|}
\hline \multirow{3}{*}{$\begin{array}{l}\text { Análise / } \\
\text { Período }\end{array}$} & \multicolumn{14}{|c|}{ in } \\
\hline & \multirow{2}{*}{\multicolumn{2}{|c|}{$\begin{array}{c}\text { Ótimo } \\
\text { (unid.) } \quad(\%)\end{array}$}} & \multirow{2}{*}{\multicolumn{2}{|c|}{$\begin{array}{c}\text { Muito Bom } \\
\text { (unid.) } \quad(\%) \\
\end{array}$}} & \multirow{2}{*}{\multicolumn{2}{|c|}{$\begin{array}{c}\text { Bom } \\
\text { (unid.) (\%) }\end{array}$}} & \multirow{2}{*}{\multicolumn{2}{|c|}{\begin{tabular}{c}
\multicolumn{2}{c}{$\begin{array}{c}\text { Mediano } \\
\text { (unid.) }\end{array}$} \\
\end{tabular}}} & \multirow{2}{*}{\multicolumn{2}{|c|}{$\begin{array}{c}\text { Sofrível } \\
\text { (unid.) } \quad(\%)\end{array}$}} & \multirow{2}{*}{\multicolumn{2}{|c|}{\begin{tabular}{c}
\multicolumn{2}{c}{ Mau } \\
(unid.) $(\%)$
\end{tabular}}} & \multirow{2}{*}{\multicolumn{2}{|c|}{$\begin{array}{l}\text { Péssimo } \\
\text { (unid.) (\% }\end{array}$}} \\
\hline & & & & & & & & & & & & & & \\
\hline \multicolumn{15}{|c|}{ Análises entre a temperatura média diária do ar: $T_{\text {med_(INMET) }}$ vS $T_{\text {med_(IAC) }}$} \\
\hline Anual & 36 & 75,0 & 10 & 20,8 & 2 & 4,2 & 0 & 0,0 & 0 & 0,0 & 0 & 0,0 & 0 & 0,0 \\
\hline Verão & 16 & 36,4 & 18 & 40,9 & 4 & 9,1 & 1 & 2,3 & 3 & 6,8 & 1 & 2,3 & 1 & 2,3 \\
\hline Outono & 30 & 66,7 & 11 & 24,4 & 3 & 6,7 & 0 & 0,0 & 0 & 0,0 & 0 & 0,0 & 1 & 2,2 \\
\hline Inverno & 24 & 52,2 & 17 & 37,0 & 3 & 6,5 & 0 & 0,0 & 2 & 4,3 & 0 & 0,0 & 0 & 0,0 \\
\hline Primavera & 21 & 44,7 & 16 & 34,0 & 5 & 10,6 & 0 & 0,0 & 2 & 4,3 & 0 & 0,0 & 3 & 6,4 \\
\hline \multicolumn{15}{|c|}{ Análises entre a temperatura média diária do ar: $T_{\text {med_INMET) }}$ vs $T_{\text {med_(Extremos) }}$} \\
\hline Anual & 29 & 60,4 & 16 & 33,3 & 1 & 2,1 & 0 & 0,0 & 0 & 0,0 & 0 & 0,0 & 2 & 4,2 \\
\hline Verão & 0 & 0,0 & 4 & 9,1 & 14 & 31,8 & 5 & 11,4 & 9 & 20,5 & 10 & 22,7 & 2 & 4,5 \\
\hline Outono & 25 & 56,8 & 14 & 31,8 & 1 & 2,3 & 1 & 2,3 & 1 & 2,3 & 0 & 0,0 & 2 & 4,5 \\
\hline Inverno & 25 & 54,3 & 13 & 28,3 & 3 & 6,5 & 1 & 2,2 & 1 & 2,2 & 1 & 2,2 & 2 & 4,3 \\
\hline Primavera & 5 & 10,6 & 16 & 34,0 & 13 & 27,7 & 3 & 6,4 & 7 & 14,9 & 0 & 0,0 & 3 & 6,4 \\
\hline
\end{tabular}
para doze localidades brasileiras ( 4 × $12=48$ pontos para cada ano e estação). 


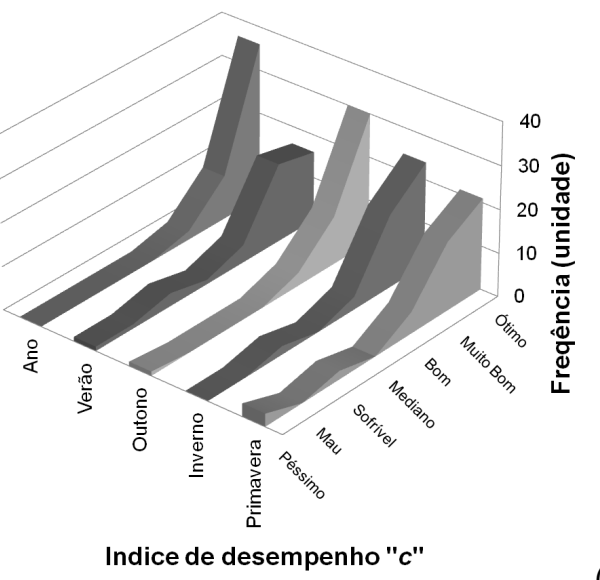

ndice de desempenho " $c$ " (b)

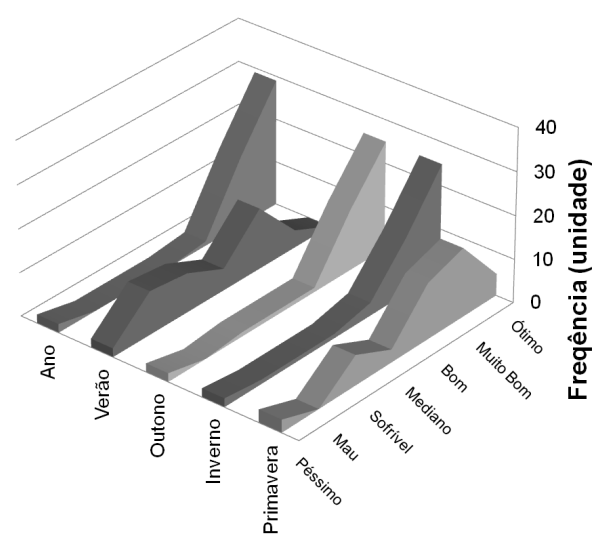

Indice de desempenho " $c$ "

FIGURA 2 - Frequência dos índices de desempenho "c" de Camargo \& Sentelhas (1997) obtidos nas análises realizadas conforme Procedimento 2, para os anos e estações do ano, contrastando: (a) $T_{\text {med }}$

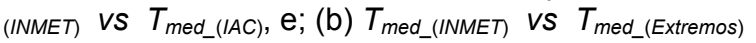

Os resultados da Tabela 4 e Figura 2 evidenciam que cuidados ainda maiores devem ser tomados na utilização dos métodos do IAC e Extremos (principalmente este último) para modelos ou procedimentos que utilizam temperatura média diária do ar baseando-se em menor período (número de dias), como ocorre, por exemplo, em cálculos da evapotranspiração de referência, soma térmica, balanço de energia, fluxo de calor, entre outros, para o ciclo de uma cultura anual.

Lima \& Ribeiro (1998), analisando 23 localidades no Estado do Piauí nos meses de janeiro e julho, com pelo menos seis anos de observação, ajustaram séries de dados de temperatura pelo método dos mínimos quadrados em função da altitude, latitude e longitude. Os autores verificaram que a altitude foi a variável mais significativa na estimativa da temperatura do ar. No presente trabalho, uma série de análises de regressão linear, envolvendo o contraste entre os valores de $R$, índices " $d$ " e " $c$ " versus a latitude $\mathrm{e}$ altitude das doze localidades estudadas também foram realizadas. No entanto, os coeficientes de determinação $\left(R^{2}\right)$ obtidos nas análises foram baixíssimos, indicando que não houve qualquer tipo de associação entre o coeficiente $(R)$ e índices (" $d$ " e " $c$ ") com a latitude e altitude das localidades. Os melhores resultados obtidos entre todas as análises realizadas com os Procedimentos 1 e 2 foram: $R^{2}=$ 0,427 (Latitudes vs valores de $R$ ); $R^{2}=0,551$ (Latitudes vs Índices “ $d$ "); $R^{2}=0,679$ (Latitudes vs Índices " $c$ "); $R^{2}=0,372$ (Altitudes vs valores de $R$ ); $R^{2}=0,282$ (Altitudes vs Índices “ ${ }^{\prime \prime}$ ); e, $R^{2}=0,395$ (Altitudes vs Índices "c").

\section{CONCLUSÕES}

Em relação ao método do INMET (padrão), o método do IAC estima melhor a temperatura média diária do ar que o método dos Extremos, para o período anual e estações do ano das localidades estudadas. O método dos Extremos tem sérias restrições para estimar a temperatura média diária do ar, principalmente estações do verão e primavera.

Os métodos do IAC e Extremos devem ser testados para estimar a temperatura média diária do ar em uma determinada localidade, antes de ser utilizada generalizadamente em atividades experimentais, principalmente nas estações do verão e primavera.

Não houve influência das coordenadas geográficas latitude e altitude no desempenho das estimativas da temperatura média diária do ar com os métodos do IAC e Extremos para as localidades estudas.

\section{REFERÊNCIAS}

1. ANDRADE, F. F. et al. Estimativa da temperatura média do ar em ambiente protegido cultivado com tomateiro Pelotas: Universidade Federal de Pelotas, 2005. 4 p.

2. BRASIL. Ministério da Ciência e Tecnologia. Instituto Nacional de Pesquisas Espaciais. Centro de Previsão de Tempo e Estudos Climáticos (CPTEC). Plataforma de Coleta de Dados (PCDs). Dados Históricos. Disponível em: <http:// satelite.cptec.inpe.br/PCD/> Acessado em: 15/02/2009.

3. CAMARGO, A. P.; SENTELHAS, P. C. Avaliação do desempenho de diferentes métodos de estimativa da evapotranspiração potencial no Estado de São Paulo. Revista Brasileira de Agrometeorologia, v. 5, n. 1, p. 89-97, 1997.

4. CARGNELUTTI FILHO, A.; MATZENAUER, R.; TAVARES MALUF, J. R. Variabilidade temporal e espacial do tamanho de amostra para estimativa das médias mensais de temperatura máxima do ar no Estado do Rio Grande do Sul. Revista Brasileira Agrometeorologia, v. 14, n. 1, p. 76-84, 2006.

5. LEITHOLD, L. O cálculo: com geometria analítica. São Paulo: HARBRA, 1977. v. 1. 526 p.

Scientia Agraria, Curitiba, v.11, n.5, p.407-416, Sept./Oct. 2010. 
JERSZURKI, D. \& SOUZA, J.L.M. Estimativa da temperatura média diária do...

6. LIMA, M. G.; RIBEIRO, V. Q. Equações de estimativa da temperatura do ar para o estado do Piauí. Revista Brasileira de Agrometeorologia, v. 6, n. 2, p. 221-227, 1998.

7. NAGHETTINI, M; PINTO, E. J. A. Hidrologia estatística. Belo Horizonte: CPRM, 2007. 552 p.

8. NECHET, D.; PRESTE, A. C. Comparação de médias diárias e mensais de temperatura do ar obtidos por vários métodos. In: CONGRESSO DA FEDERAÇ̃̃O LATINO-AMERICANA E IBÉRICA DE SOCIEDADE DE METEOROLOGIA, 8., CONGRESSO BRASILEIRO DE METEOROLOGIA, 10., 1998, Brasília. Anais... Brasília: Sociedade Brasileira de Meteorologia, 1998.

9. PEZZOPANE, J. E. M et al. Espacialização da temperatura do ar no Estado do Espírito Santo. Revista Brasileira Agrometeorologia, v. 12, n. 1, p. 151-158, 2004.

10. REICHARDT, K; TIMM, L. C. Solo, planta e atmosfera: conceitos, processos e aplicações. Barueri: Manole, 2004 $478 \mathrm{p}$.

11. SERRA, A. Climatologia do Brasil. Boletim Geográfico, v. 33, n. 243, p. 53-119, 1974

12. WILLMOTT, C. J. et al. Climatology of terrestrial seasonal water cicle. Internation Journal of Climatology, v. $5, p$. 589-606, 1985.

Recebido em 27/08/2009 Aceito em 13/10/2010 